\title{
MARACATU NAÇÃO E GRUPOS PERCUSSIVOS: DIFERENÇAS, CONCEITOS E HISTÓRIAS
}

\author{
"Maracatus Nação" and percussive groups: \\ differences, concepts and Histories
}

\author{
Ivaldo Marciano França Lima ${ }^{1}$
}

\begin{abstract}
RESUMO
O presente artigo objetiva discutir e analisar o maracatu nação enquanto fenômeno sócio-histórico-cultural presente nas cidades do Recife, Olinda, Jaboatão e Igarassu, localizadas na região metropolitana da capital pernambucana. Tal análise se fez buscando estabelecer as diferenças principais existentes entre os maracatus nação e os grupos percussivos, resultantes em sua maioria no contexto posterior ao Movimento Mangue. Para esta delimitação, procurou-se mostrar as diferenças entre as duas manifestações, bem como os significados do conceito de nação utilizados no âmbito dos maracatus. O trabalho também discute outros aspectos relacionados aos maracatus, a exemplo dos sotaques, historiografia e o "problema" das origens.
\end{abstract}

Palavras chave: maracatu nação; grupos percussivos; cultura negra; Recife.

\begin{abstract}
This article aims to discuss and analyze the "maracatus nação" as a socio-historical cultural phenomenon present in the cities of Recife, Olinda, Jaboatão and Igarassu, located in the metropolitan area of Recife. Such analysis was done in order to establish the main differences between the "maracatus nação" and the percussive groups, resulting mostly in the context of post-Mangue Movement. For this delimitation, we tried to show the differences between the two events, as well as the meanings of the concept of nation, used under maracatus. The work also discusses other aspects related to maracatus, like the differences in the musical accents, historiography and the "problem" of origins.

Keywords: "Maracatus Nação"; percussive groups; black culture; Recife.

1 Prof. Adjunto do Departamento de Educação. Colegiado de História, campus II (Alagoinhas). UNEB - Universidade do Estado da Bahia.
\end{abstract}


Para discorrer a respeito dos maracatus nação pernambucanos, suas práticas, costumes e sociabilidades, necessito definir de forma clara que estes grupos se constituem em importante elemento da cultura negra. Portanto, não são simplesmente "componentes integrantes da cultura popular pernambucana", como escrevem ou afirmam alguns (e algumas!) estudiosos e intelectuais Brasil afora. Aliás, parafraseando Roger Chartier, nos dias atuais é tarefa por demais difícil (e ingrata!) estabelecer as diferenças entre uma manifestação da cultura popular e uma erudita. ${ }^{2}$ Entretanto, nem de longe posso admitir que um maracatu nação, construído e praticado por homens negros e mulheres negras em sua maioria (salvo raríssimas exceções, como eu, por exemplo, homem de cor branca e maracatuzeiro há mais de vinte anos), possa ser visto como parte de uma mesma cultura, e dotado dos mesmos sentidos, que um grupo percussivo. Estes, durante o carnaval, invadem as ruas da cidade do Recife, mostrando que não há nada de ingênuo ou inocente nas festas carnavalescas da capital pernambucana. Este é o tema central deste artigo, buscar problematizar as fronteiras identitárias das duas manifestações culturais, negociações e conflitos em que estão envolvidas no disputado mercado cultural pernambucano.

\section{Antes de tudo, vamos pensar alguns conceitos}

Quando me refiro aos maracatus nação, a questão acima torna-se bastante emblemática no sentido de mostrar que estes grupos não podem e não devem ser entendidos como parte de uma cultura popular brasileira genérica. Correndo os riscos de ser tomado como contraditório, uma vez que mais à frente irei reivindicar a brasilidade para os homens negros e as mulheres negras deste país, afirmo que suas práticas e costumes não podem ser vistos como integrantes de um grande cadinho de junções e justaposições culturais, feitos por pessoas anônimas, sem rostos, nomes, cores e cheiros, como o folclore numa determinada época costumava definir. Não se trata tão somente de afirmar serem os maracatus diferentes de outras manifestações

2 CHARTIER, Roger. "Cultura Popular": revisitando um conceito historiográfico. Estudos Históricos, Rio de Janeiro, v. 8, n. 16, 1995. 
culturais destituídas do componente racial, mas penso que entendê-los apenas como parte da cultura popular é atribuir para diferentes práticas sentidos homogêneos. Isto, contudo, não me exime de afirmar que o conceito de raça, em certa medida, traz consigo aspectos que levam à homogeneidade.

O maracatu nação pode até ser entendido como uma manifestação da cultura popular brasileira, desde que se entenda que é feito em determinado contexto histórico-cultural por pessoas que estão referenciadas em uma cultura negra. A cultura negra, neste aspecto, é, a meu ver, identificada com práticas e costumes feitos de forma comunitária, que trazem consigo sentidos compartilhados por grupos que dispõem modos, ofícios e saberes de formas complexas e dispostas para diferentes pessoas, o que não significa dizer que inexistam tensões e conflitos nestes agrupamentos.

Há conflitos, disputas, pessoas querendo tomar o lugar do rei, do mestre do batuque, bem como tensões por dinheiro, dentre outras questões. Mas nem tudo se constitui em disputas ou contendas nos maracatus. Existe o compartilhamento de práticas! E isto, por assim dizer, constitui parte das diferenças entre o maracatu nação e o grupo percussivo. ${ }^{3}$

Ao que me parece, o recorte racial, tendo como pressuposto os sentidos e as formas como as práticas são compartilhadas, se constitui na melhor maneira de definir as diferenças (quando estas existem, evidente!) e assim poder melhor traduzi-las. Em relação aos maracatus, gostaria de doravante nomeá-los como práticas pertencentes ao que denomino por cultura negra. Refiro-me ao termo "cultura negra" não como um arrazoado de palavras justapostas, mas como um conceito que expressa a parte fundamental do maracatu, sobretudo em seus principais aspectos quotidianos. Categoricamente rejeito os conceitos "afro-brasileiro" e "afrodescendente" por entender que ambos não definem de forma precisa, eu diria, um conjunto de práticas e costumes construídos, elaborados e reelaborados por homens e mulheres nascidos neste país, que devem e precisam ser vistos como cidadãos e cidadãs com plenos direitos em tudo o que diz respeito à brasilidade. Importante também ressaltar que os conceitos acima citados aludem à ideia de origem e, de certa forma, apontam para a biologização da História. ${ }^{4}$

3 LIMA, Ivaldo Marciano de França; GUILLEN, Isabel Cristina Martins. Cultura afrodescendente no Recife: maracatus, valentes e catimbós. Recife: Bagaço, 2007.

4 LIMA, Ivaldo Marciano de França. Por uma história a partir dos conceitos: África, cultura negra e lei 10.639/2003. Reflexões para desconstruir certezas. A Cor das Letras, Feira de Santana, v. 1, n. 12 , p. $125-152,2011$. 
Não posso deixar de ressaltar que as identidades (assim como os conceitos!) são construídas, o que de certa forma me deixa à vontade para mostrar que o conceito de cultura negra não alude à essencialização da prática e do fazer cultural. Estas reflexões são importantes na medida em que, a partir delas, estabeleço distinções entre os conceitos. Também considero fundamental pensar a respeito da relação existente entre os negros e negras de nosso país com a ideia de que sejam estes e estas descendentes do continente africano.

A meu ver, entender tal associação de forma naturalizada, algo que ocorre na maioria dos trabalhos que têm as práticas e os costumes culturais negros como tema, é incorrer em confusões entre cultura e natureza. Categoricamente, portanto, rejeito a ideia de que todo homem negro e mulher negra sejam, necessariamente, descendentes exclusivos de pessoas do continente africano, daí considerar incorreto o uso dos conceitos "afro-brasileiro" e "afrodescendente". Nesse sentido, categorizo as identidades como parte da cultura, logo, esta não pode ser entendida por conceitos que remetem diretamente à ideia de origem, bem como a uma relação essencializada e naturalizadora. ${ }^{5}$

Portanto, no meu entendimento, os maracatus constituem parte da cultura negra deste país. Cultura, por ser uma construção dotada de significados intimamente ligados com as "leituras" do quotidiano. Negra, por entender que, devido à segregação tácita a que foram impostos, os negros e negras constituíram práticas e costumes que expressam suas visões de mundo, pontos de vista, memórias, sociabilidades, dentre outras questões. Os conceitos de "afro-brasileiro" e "afrodescendente" retiram, mesmo que

5 Sobre o conceito de identidade, em suas diferentes perspectivas, ver: BAUMAN, Zygmunt. Identidade. Rio de Janeiro: J. Zahar, 2005; D’ADESKY, Jacques. Pluralismo étnico e multiculturalismo-racismos e antirracismos no Brasil. Rio de Janeiro: Pallas, 2001; ELIAS, Norbert. A sociedade dos individuos. Rio de Janeiro: J. Zahar, 1994; GOFFMAN, Erving. A representação do eu na vida cotidiana. Petrópolis: Vozes, 1985; GOFFMAN, Erving. Estigma. Notas sobre a manipulação da identidade deteriorada. 4. ed. Rio de Janeiro: Guanabara, 1988; HALL, Stuart. A identidade cultural na pós-modernidade. Rio de Janeiro: DP\&A, 2002; HALL, Stuart. Da diáspora. Identidades e mediações culturais. Belo Horizonte: Ed. UFMG, 2003; HALL, Stuart. Identidade cultural e diáspora. Revista do Patrimônio Histórico e Artístico Nacional, Rio de Janeiro, v. 4, p. 68-75, 1996; HALL, Stuart. Quem precisa da identidade? In: SILVA, Tomaz Tadeu da (Org.). Identidade e diferença. A perspectiva dos estudos culturais. Petrópolis: Vozes, 2000. p. 103-133; LOVEJOY, Paul E. Identidade e a miragem da etnicidade. A jornada de Mahhomah Gardo Baquaqua para as Américas. Afro-Ásia, Salvador, v. 1, n. 27, p. 9-39, jan.-jun. 2002; MACHADO, Cristina Gomes. Multiculturalismo: muito além da riqueza e da diferença. Rio de Janeiro: DP\&A, 2002; OLIVEIRA, Roberto Cardoso de. Caminhos da identidade. Ensaios sobre etnicidade e multiculturalismo. São Paulo: UNESP/ Brasília: Paralelo 15, 2006. 
implicitamente, a brasilidade e a cidadania dos negros e negras em nosso país, quebrando, inclusive, o paradigma da brasilidade indistinta, defendida com tanto vigor por Gilberto Freyre em grande parte de sua obra, sobretudo a que foi expressa em Casa grande \& senzala ${ }^{6}$ Mesmo que na prática alguns sejam mais brasileiros do que outros, mostrando que esta "brasilidade indistinta" só serve para os homens e mulheres de pele branca e cabelos lisos. Os conceitos "afro-brasileiro" e "afrodescendente" se constituem em armadilhas que fazem dos negros e negras deste país verdadeiros estrangeiros, ou, na melhor das hipóteses, cidadãos e cidadãs de segunda classe. ${ }^{7}$

O fato de serem brasileiros, entretanto, não significa dizer que são iguais aos não negros. Não preciso de grande esforço para indicar que, entre os brasileiros e as brasileiras, os problemas relacionados às relações raciais são pautados por preconceitos e discriminações diversas. ${ }^{8}$ Eis os porquês de minha insistência em entender e nomear práticas e costumes construídos e mantidos por negros e negras pelo conceito de cultura negra. Para esta questão, é fundamental perceber as diferenças, sobretudo quando elas são reveladoras de tensões, conflitos e negociações. A produção das práticas e costumes culturais se traduz, nesse sentido, como o local privilegiado das diferenças.

\section{Mas, o que é mesmo um maracatu?}

O maracatu pode ser definido como uma manifestação cultural dotada de elementos diversos. Dispõe de dança, canto, fantasias e estilo musical

6 FREYRE, Gilberto. Casa grande \& senzala. São Paulo: Global, 2006.

7 Uma excelente discussão sobre a ideia do estrangeiro na sua própria terra, que não está diretamente relacionada com a rejeição aos conceitos citados, pode ser vista em: NAXARA, Márcia Regina Capelari. Estrangeiro em sua própria terra. Representações do brasileiro - 1870/1920. São Paulo: Annablume/FAPESP, 2002.

8 GUIMARÃES, Antonio Sérgio Alfredo. Preconceito e discriminação: queixas de ofensas e tratamento desigual dos negros no Brasil. 2. ed. São Paulo: Ed. 34, 2004; GUIMARÃES, Antonio Sérgio Alfredo. Preconceito racial. Modos, Temas e Tempos. São Paulo: Cortez, 2008; GUIMARÃES, Antonio Sérgio Alfredo. Racismo e antirracismo no Brasil. 2. ed. São Paulo: Ed. 34, 2005; GUIMARÃES, Antonio Sérgio Alfredo; HUNTLEY, Lynn. Tirando a máscara. Ensaios sobre o racismo no Brasil. São Paulo: Paz e Terra, 2000; HASENBALG, Carlos. Discriminação e desigualdades raciais no Brasil. Belo Horizonte: Ed. UFMG; Rio de Janeiro, IUPERJ, 2005. 
próprio. Um maracatu é definido por sua música, cantada em geral por um mestre, que é acompanhado de batuqueiros, tocando afaias (os tambores), caixas, taróis, mineiros (espécie de ganzá) e gonguês (instrumento de ferro com uma campânula, percutida por um pedaço de madeira).

Existem maracatus-nação que possuem fortes ligações com as religiões de terreiro, a exemplo do xangô, e até bem pouco tempo houve quem afirmasse serem eles simples extensões carnavalescas destas. No entanto, a relação dos maracatus-nação com o sagrado não se resume aos orixás, pois há grupos em que a jurema e a umbanda também estão presentes. A jurema pode ser definida como uma religião em que são cultuados vários tipos de entidades. Nela existem mestres e mestras, caboclos e caboclas, índios e índias, pretos e pretas velhas, exus e pombagiras. ${ }^{9}$ Esta religião encontra-se espalhada pelo Nordeste e pode ser vista em forma isolada ou associada à umbanda. Quanto a esta última, trata-se de uma religião com características nacionais, dotada de elementos das filosofias kardecista e cristã e da religião dos orixás. Nela existem dois lados, o do bem e o do mal, cada qual com sete linhas, sendo estas dotadas de sete falanges. ${ }^{10}$

Normalmente vemos vários grupos desfilando no carnaval, constituídos de um cortejo real, acompanhados de um conjunto de percussão, mais conhecido como batuque. Alguns maracatus usam instrumentos que foram incorporados recentemente, a exemplo do abê e do atabaque. No geral, suas músicas, também conhecidas por toadas, são estruturadas em um verso constituído de uma chamada, a primeira voz, feita pelo mestre, e a resposta, a segunda voz, normalmente entoada pelos demais integrantes do maracatu:

Mandei fazer uma casa, com a janela para o mar (chamada) Só para Dona Joventina, rainha de Portugal (resposta).

9 VANDEZANDE, René. Catimbó. Pesquisa exploratória sobre uma forma nordestina de religião mediúnica. Dissertação (Mestrado em Sociologia) - Programa de Pós-Graduação em Sociologia, Universidade Federal de Pernambuco, Recife, 1975; BRANDÃO, Maria do Carmo; RIOS, Luis Felipe. O catimbó-jurema do Recife. In: PRANDI, Reginaldo (Org.). Encantaria brasileira. Rio de Janeiro: Pallas, 2001. p. 160-181; ASSUNÇÃO, Luiz. O reino dos mestres: a tradição da jurema na umbanda nordestina. Rio de Janeiro: Pallas, 2006.

10 NEGRÃO, Lísias. A umbanda como expressão de religiosidade popular. Religião e sociedade. Rio de Janeiro: Civilização Brasileira, 1979; NEGRÃO, Lísias. Umbanda, entre a cruz e a encruzilhada: formação do campo umbandista em São Paulo. São Paulo: EDUSP, 1996; BIRMAN, Patrícia. O que é Umbanda? São Paulo: Brasiliense, 1983; MEYER, Marlyse. Maria Padilha e toda a sua quadrilha: de amante de um rei de Castela a Pombagira de Umbanda. São Paulo: Duas Cidades, 1993. 
A bandeira é brasileira, nossos reis vêm de Luanda (chamada) Salve Dona Joventina, princesa pernambucana (resposta). ${ }^{11}$

Seus personagens estão distribuídos em uma verdadeira corte. Há o rei, a rainha, príncipe e princesa, duque e duquesa, vassalos, escravos, lanceiros, baianas e damas do paço. Estas últimas trazem consigo as bonecas, também conhecidas como calungas. Todos (e todas) os personagens da corte costumam vir trajando fantasias ricamente adornadas. A dança é feita de forma séria, desprovida de coreografias complexas, como ocorre nas quadrilhas juninas. Porém, alguns grupos novos, a exemplo do Leão da Campina e Aurora Africana, trazem consigo danças coreografadas, sobretudo pela grande quantidade de quadrilheiros que toma parte nestes maracatus durante o carnaval. Nestes maracatus, a "seriedade" dos desfilantes é transformada em risos e outros trejeitos. As manifestações culturais dialogam e se influenciam!

Os desfiles contemporâneos ocorrem em passarelas organizadas especialmente no carnaval, constituindo-se em um verdadeiro espetáculo visual. Alguns maracatus trazem em suas fileiras perto de mil integrantes, especialmente dispostos e organizados no dia do concurso carnavalesco, que geralmente ocorre no domingo de carnaval. Sim, os maracatus desfilam durante o período momesco, mas isso não me autoriza a dizer que eles não saiam em outras datas, sobretudo quando convidados pelo poder público ou empresa privada, em troca de um bom cachê. Afinal de contas, os maracatus possuem gastos, como qualquer outra instituição.

\section{Os batuques: quem ouviu um, ouviu todos?}

Os maracatus tocam maracatu. Óbvio, não é? Mas isso não nos autoriza, prezado leitor e estimada leitora, a afirmar que todos os batuques

11 Nestas toadas compartilhadas por diferentes maracatus, é comum se deparar com as adaptações nas letras. Neste caso, Dona Joventina é a calunga do Maracatu Nação Estrela Brilhante, mas é perfeitamente possível escutar estas toadas com outros nomes, a exemplo de Isabel, Emilia, dentre outras. Estes nomes também são de calungas pertencentes a outros maracatus nação. 
são iguais. Há influências recíprocas entre as nações, mas há também as diferenças, que na maioria das vezes constituem identidades construídas a partir das práticas compartilhadas pelo grupo em questão. O maracatu é executado, enquanto música, exclusivamente por instrumentos percussivos, ao menos até agora. As mudanças estão em curso! Há dois tipos de maracatus desfilando nos carnavais pernambucanos. Os maracatus nação, sobre os quais venho discorrendo desde o início destas páginas, e os maracatus de orquestra, que trazem consigo instrumentos de sopro, o caboclo de lança e uma música bastante acelerada. Esta última se trata de outra manifestação cultural, diferente dos maracatus nação (que são também conhecidos como baque virado). ${ }^{12}$

Os maracatus de orquestra, também conhecidos como "rurais", são dotados de outra constituição rítmica. Enquanto o nação ou baque virado é acompanhado por uma orquestra percussiva, em que sobressaem as afaias, o maracatu rural é constituído por um "terno" composto de "poica" (espécie de cuíca), tambor, gonguê de duas campânulas, caixa e instrumentos de sopro, que podem ser o pistão ou trombone de vara. As diferenças musicais são muito grandes! Em um passado recente, praticamente não havia diferenças entre os maracatus nação e o de orquestra. Ou pelo menos estas não eram percebidas da forma como as vemos hoje. ${ }^{13}$

Esta distinção entre os dois tipos foi pensada e estabelecida pelo maestro Guerra Peixe, que esteve no Recife entre os anos de 1949 e 1952, estudando os xangôs, maracatus e a cultura dita "popular" em geral. Até a publicação de seu livro, Maracatus do Recife, não havia consenso entre os estudiosos sobre as diferenças entre essas formas de expressão. Guerra Peixe afirmou que os maracatus se distinguiam principalmente pelos conjuntos musicais utilizados, daí a definição dos termos ainda hoje usados

12 BENJAMIN, Roberto. Maracatus rurais de Pernambuco. In: PELLEGRINI FILHO, Américo (Org.). Antologia de folclore brasileiro. São Paulo: Edart, 1982. p. 199-212; BENJAMIN, Roberto. Maracatus rurais. Folclore (FUNDAJ - Centro de Estudos Folclóricos), Recife, n. 12, 1976; NASCIMENTO, Mariana Cunha Mesquita do. João, Manoel, Maciel Salustiano. Três gerações de artistas populares recriando os folguedos de Pernambuco. Recife: Reviva, 2005.

13 Sobre a questão relacionada com a história da distinção entre os dois tipos dos maracatus existentes em Pernambuco, ver: GUILLEN, Isabel Cristina Martins. Maracatus-nação entre os modernistas e a tradição: discutindo mediações culturais no Recife dos anos 1930 e 1940. Clio, Recife, v. 1, p. 107-135, jan.-jun. 2003; LIMA, Ivaldo Marciano de França. Maracatus e maracatuzeiros, batendo afaias, fazendo histórias. Recife, 1930-1945. Recife: Edições Bagaço, 2008. 
para nomear os dois tipos de maracatus: baque solto e baque virado. ${ }^{14}$ No caso dos maracatus nação, já sabemos, prezado leitor e estimada leitora, que trazem consigo instrumentos de percussão e que já os descrevemos acima. Em geral podem-se identificar seis grandes estilos/sotaques/baques que, grosso modo, se encontram presentes nos batuques dos maracatus.

O primeiro estilo é feito pelo Cambinda Estrela. Possui um sotaque exclusivo, feito apenas por esse grupo (que por acaso é o que eu fiz parte!). O segundo é executado pelo Estrela Brilhante de Igarassu. Também é exclusivo deste grupo. $\mathrm{O}$ terceiro pode ser encontrado no Leão Coroado de Águas Compridas (que reivindica ser o continuador, juntamente com o Centro Grande Leão Coroado da Bomba do Hemetério, do antigo grupo homônimo que era liderado pelo famoso Luiz de França). Este sotaque é feito também pelo Maracatu Tigre, uma vez que os integrantes deste desfilavam no grupo de Águas Compridas, antes de constituírem seu próprio grupo. $\mathrm{O}$ quarto é feito pelo Centro Grande Leão Coroado da Bomba do Hemetério, que substituiu o batuque do Encanto da Alegria, quando este era regido pelo Mestre Toinho. Em 2010, este maracatu (Encanto da Alegria) aderiu ao estilo do Estrela Brilhante do Recife.

Os quatro estilos de batuques acima descritos, em geral, não possuem força significativa perante os demais sotaques de maracatu, que são influenciados ou pelo Estrela Brilhante do Recife (o quinto estilo) ou pelo Porto Rico (o sexto estilo). Advirto o leitor e a leitora de que os termos primeiro, segundo, terceiro, etc. não se constituem em juízos relacionados com a antiguidade ou qualidade dos sotaques. Pode-se perfeitamente inverter as ordens de apresentação sem prejuízo algum no entendimento.

Também existem maracatus em que os seus batuques executam estilos compostos a partir dos dois anteriores. Estas influências sonoras podem ser explicadas por motivos diversos, mas, no fundamental, as pessoas só imitam e reproduzem aquilo que faz sucesso, e não seria diferente entre os maracatuzeiros e as maracatuzeiras. Tanto o Estrela Brilhante do Recife como o Porto Rico são os maracatus que mais ganharam concursos carnavalescos nas duas últimas décadas, assim como são aqueles que mais realizam viagens pelo Brasil e exterior. Portanto, são os que mais despertam fascínios e encantamentos. Esta dinâmica mostra que, ao contrário do que

14 PEIXE, Guerra. Maracatus do Recife. 2. ed. Recife: Prefeitura da Cidade do Recife/Irmãos Vitale, 1980 
foi escrito por alguns estudiosos, especialmente os folcloristas, os maracatus nação estão em permanente diálogo com o presente e a todo tempo incorporam mudanças em sua constituição.

\section{Maracatus do presente e do passado: nomes e histórias}

Há atualmente perto de vinte e oito maracatus nação existentes na região metropolitana do Recife. Excetuando quatro grupos, todos os demais se encontram organizados na Associação dos Maracatus Nação de Pernambuco-AMANPE..$^{15}$ Alguns grupos da atualidade afirmam serem os herdeiros de grupos homônimos do passado, chegando mesmo a reivindicarem para si o lugar de continuidades, de "resgates do passado", compartilhado pelo uso comum do nome do grupo. Este é o caso do Estrela Brilhante do Recife, que se apresenta como um maracatu com mais de cem anos e que está "continuando" a história do grupo de mesmo nome, fundado por Cosme Damião no início do século XX. Porto Rico, Cambinda Estrela e Elefante também podem ser compreendidos por esta perspectiva. ${ }^{16}$

Ressalte-se que nem as formas de tocar, as pessoas ou as comunidades em que se encontram sediados atualmente são as mesmas dos grupos reivindicados. E nesse aspecto, por mais que os maracatus nação estejam envoltos em discursos de tradição e continuidade, quase todos podem

15 Almirante do Forte, Aurora Africana, Axé da Lua, Cambinda Estrela, Encanto da Alegria, Encanto do Dendê, Encanto do Pina, Estrela Brilhante do Recife, Estrela Dalva, Estrela de Olinda, Gato Preto, Leão da Campina, Linda Flor, Nação de Luanda, Oxum Mirim, Porto Rico, Raízes de Pai Adão, Sol Nascente, Tigre, Tupinambá, Lira do Morro da Conceição, Rosa Vermelha, Leão de Judá, Leão Coroado da Bomba do Hemetério, Cambinda Africana, Elefante, Estrela Brilhante de Igarassu e Leão Coroado de Águas Compridas. Quase todos os grupos, excetuando os quatro últimos, são filiados à AMANPE - Associação dos Maracatus Nação de Pernambuco.

16 CARVALHO, Ernesto Ignácio de. Diálogo de negros, monólogo de brancos: transformações e apropriações musicais no maracatu de baque virado. Dissertação (Mestrado em Antropologia) - Programa de Pós-Graduação em Antropologia, Universidade Federal de Pernambuco, Recife, 2007. Esta é uma das mais importantes obras sobre o passado de alguns maracatus nação da cidade do Recife. Mesmo não abordando a questão relacionada com as continuidades dos maracatus, se constitui numa excelente possibilidade de encontrar, em um mesmo texto, refinamento teórico, rebuscamento literário e excelente uso das fontes, sobretudo as memórias dos mais antigos maracatuzeiros. Infelizmente é um trabalho que ainda se encontra sob a forma de dissertação, portanto, de difícil acesso ao grande público. Sua qualidade destoa da imensa maioria das teses, dissertações e monografias escritas sobre os maracatus nação. 
ser descritos como recentemente fundados. A exceção, neste caso, são os maracatus Almirante do Forte, que se encontra na mesma comunidade há mais de oitenta anos, e o Porto Rico, que, mesmo se reivindicando como o continuador de outro grupo de mesmo nome, encontra-se no Pina, sob a liderança da mesma família, desde os anos 1980.

Praticamente todos os maracatus foram fundados ao longo dos anos 1990, excetuando Almirante do Forte (fundado nos anos 1920), que é o mais antigo em relação à continuidade - à localização na mesma comunidade e pertencimento dos antigos integrantes -, Encanto do Pina, Gato Preto, Linda Flor, Porto Rico e Elefante (anos 1980). Se estabelecermos uma comparação dos maracatus nação com as escolas de samba cariocas, veremos que a ideia de tradição existente nos primeiros não se sustenta em diversos aspectos presentes nestas, a exemplo de permanência em uma mesma comunidade, bem como a participação de integrantes (em alguns casos familiares dos fundadores). Tomando estes aspectos como parâmetros, as escolas de samba cariocas possuem muito mais "tradição" do que os maracatus nação pernambucanos!

No passado existiram maracatus que, de tão significativos, deixaram marcas profundas na memória dos maracatuzeiros e maracatuzeiras do presente. Este é o exemplo do Leão Coroado de Luiz de França, que, conforme já afirmei, possui dois grupos que o reivindicam na atualidade. ${ }^{17}$ O Maracatu Indiano, que existiu entre os anos de 1940 até 1998, pode ser considerado outro grande maracatu do passado e que hoje é citado por alguns maracatuzeiros antigos como modelo de maracatu de outrora. $\mathrm{O}$ seu articulador era José Gomes e sua sede ficava no Alto do Deodato (zona norte do Recife), local em que permaneceu até a morte de seu principal responsável, nos anos 1990. Oriente Pequeno foi outro grande maracatu que desfilou pelas ruas do Recife nos anos 1910. Era articulado por Adama, apelido que lhe fez ser mais conhecido, ou José Paulino dos Santos, seu nome de batismo. Além de articulador do Maracatu Oriente Pequeno, Adama foi também um dos capoeiristas recifenses, daqueles denominados pelo termo de valentes ou "brabos". ${ }^{18}$

17 BENJAMIN, Roberto. Dona Santa e Luiz de França: gente dos maracatus. In: SILVA, Vagner Gonçalves da (Org.). Memória Afro-Brasileira. Artes do Corpo. São Paulo: Selo Negro, 2004. p. 54-76.

18 LIMA, Ivaldo Marciano de França. Adama e Nascimento Grande: valentes do Recife da Primeira República. Cadernos de Estudos Sociais, Recife, v. 22, p. 49-61, jul.-dez. 2006; CUNHA, Israel 
Cosme Damião Tavares foi o principal articulador do Maracatu Estrela Brilhante do Recife. Era praticante da jurema e viveu na primeira metade do século XX. Foi o mais célebre maracatuzeiro nos anos 1920, 1930 e 1940, tendo sido superado em fama e notoriedade por Maria Julia do Nascimento, ou Dona Santa. Esta última foi rainha do Maracatu Elefante e ainda hoje se constitui como a principal referência entre os maracatuzeiros e maracatuzeiras do Recife. Ela faleceu em 1962.

Pedro de Alcântara e Maroca Gorda foram outros dois grandes maracatuzeiros dos anos 1930. O primeiro articulava o Porto Rico de Água Fria, que era localizado na Rua da Regeneração, no bairro de mesmo nome (Água Fria). Pouco se sabe sobre seu articulador, inclusive o ano de sua morte. No presente há a controvérsia em torno de seu apelido, uma vez que os articuladores do atual Porto Rico afirmam que Pedro de Alcântara era conhecido por "Zé da Ferida", mas o seu sobrinho, Neguinho do Caminhão, bem como outros maracatuzeiros antigos, se referiu ao mesmo como "Pedro da Ferida". Quanto a Maroca Gorda, as dúvidas são ainda maiores, uma vez que sequer sabemos por certo o seu verdadeiro nome (Maria Francisca Britto?). Sabe-se que ela era parteira e afamada juremeira na comunidade da Mangabeira, na zona norte do Recife. O seu maracatu era o Dois de Ouro de Casa Amarela.

José Tercílio foi um dos muitos mestres maracatuzeiros que o Recife já possuiu. Seu maracatu era o Cambinda Estrela, que na atualidade é reivindicado pelo grupo homônimo localizado em Chão de Estrelas, zona norte do Recife. Luiz de França foi o principal articulador do Leão Coroado, entre as décadas de 1960 e 1990 . Faleceu no ano de 1997 e ficou conhecido por ser um dos principais mantenedores de um estilo de maracatu "tradicional". Pode-se afirmar que seu maracatu foi um dos principais grupos em atividade nos anos 1960 e 1970, disputando a hegemonia na cidade do Recife com o Indiano e o Estrela Brilhante (este último apenas nos anos 1970, quando Madalena deixou o Indiano e ingressou em suas fileiras).

Porém, nem só de passado vivem os maracatuzeiros e as maracatuzeiras. Na atualidade os grupos reproduzem verdadeiros espetáculos na passarela oficial do carnaval recifense. Os dois maiores grupos da contemporaneidade

Ozanan de Souza. Capoeira e capoeiras entre a Guarda Negra e a Educação Física no Recife. Dissertação (Mestrado em História) - Programa de Pós-Graduação em História da Universidade Federal de Pernambuco, Recife, 2013. 
são o Porto Rico e o Estrela Brilhante do Recife. Ambos se revezam como campeões do carnaval há mais de quinze anos. Para quem pensar que os maracatus são imutáveis, parados no tempo e no espaço, precisam lembrar que os seres humanos estão sempre criando e que esta história de manutenção de tradição, repassada de pai para filho, conforme o conceito de repetição acrítica criado por Câmara Cascudo, não possui efetividade no seio dos maracatus nação. ${ }^{19}$ Estes são o lugar da invenção e da criação. Ainda bem!

\section{Um pouco de historiografia: os maracatus nação entre os estudiosos}

Os maracatus nação foram retratados e descritos por muito tempo como sinônimos de práticas feitas por escravos africanos. Pereira da Costa, famoso folclorista pernambucano, já em 1908 prognosticava sua extinção devido à escassez de africanos no país e pelo fato de os seus descendentes preferirem imitar os costumes da sociedade branca em detrimento dos seus. ${ }^{20}$ Foi este folclorista quem fez a mais completa e antiga descrição de um maracatu, sendo esta até hoje usada como prova por parte de alguns estudiosos para afirmar o fato de que os grupos não mudaram substantivamente ao longo dos anos. ${ }^{21}$ Katarina Real, antropóloga norte-americana, seguiu os passos de Pereira da Costa e também prognosticou nos anos 1960 o fim próximo e inevitável desta manifestação cultural. ${ }^{22}$ Outros estudiosos escreveram sobre os maracatus do Recife, ora afirmando-os como meras sobrevivências de um passado remoto, ora como folguedos ou brinquedos que serviam apenas para a animação e lazer entre seus integrantes. ${ }^{23}$

19 CASCUDO, Câmara. Vaqueiros e cantadores. Rio de Janeiro: Ediouro, 2000.

20 COSTA, F. A. Pereira da. Folk-lore pernambucano. Subsídios à história da poesia popular em Pernambuco. Revista do Instituto Histórico e Geográfico Brasileiro, Tomo LXX, parte II, Rio de Janeiro, 1908.

21 Outra descrição bastante recuada no tempo pode ser vista em: CARVALHO, Rodrigues. Cancioneiro do Norte. 2. ed. aumentada. Parahyba do Norte: Typ. da Livraria São Paulo, 1928.

22 REAL, Katarina. O folclore no carnaval do Recife. 2. ed. Recife: Fundação Joaquim Nabuco/Ed. Massangana, 1990.

23 ALMEIDA, Renato. História da música brasileira. Rio de Janeiro: F. Briguiet \& Comp., 1942; ALMEIDA, Renato. Vivência e projeção do folclore. Rio de Janeiro: Livraria Agir, 1971; ALVARENGA, Oneyda. Maracatu. In: Música Popular Brasileira. Porto Alegre: Globo, 1950; SILVA, Leonardo 
Houve também quem interpretasse os maracatus como heranças africanas, ou simplesmente imitações das cortes europeias. ${ }^{24}$ Os maracatus, no entanto, são bem brasileiros e compostos de saberes e modos de fazer os mais variados possíveis, a exemplo da afaia, espécie de tambor com a afinação feita por amarração de cordas (igualzinho aos que eram utilizados pelos exércitos europeus!), bonecas de cera ou de pano (assemelhadas aos ídolos ou bonecos existentes na região da África centro-ocidental) e grandiosos guarda-sóis (muito usados pelos antigos soberanos do Daomé - os dadás - e de Oyó - os alafins). Como é possível ver, os maracatus foram construídos por brasileiros que se utilizaram de heranças e costumes os mais variados que se possam imaginar, mostrando na prática que a tradição se mantém de forma bastante dinâmica em um complexo processo de fazer e refazer constantes. Até mesmo porque isso de "manter uma tradição" parada no tempo e no espaço, como algo conservado no formol, não é tarefa para seres humanos, criativos por natureza. ${ }^{25}$

Os maracatus são muito mais complexos do que podemos imaginar e os conceitos de folguedo, brinquedo ou sobrevivência cultural não os explicam por completo. Ao contrário, os infantilizam! Até hoje, em meio às dificuldades enfrentadas por suas comunidades, eles saem às ruas durante o carnaval e constituem excelentes oportunidades para seus integrantes construírem suas identidades, promoverem sociabilidades, se afirmarem politicamente e se divertirem. Não há como reduzir os maracatus a um só sentido, tampouco devem ser vistos como meros objetos com funções programadas, como pensaram (e pensam!) alguns estudiosos. A zona norte do Recife é a região que possui a maior concentração de maracatus nação. Lá se encontram sediados o Centro Grande Leão Coroado, Cambinda Estrela, Sol Nascente, Elefante, Encanto da Alegria, Estrela Brilhante do Recife, Encanto do Dendê, Cambinda Africano, Gato Preto, Encanto do Dendê, Linda Flor, dentre outros.

Dantas. A corte dos reis do congo e os maracatus do Recife. Notícia Bibliográfica e Histórica, Campinas: PUC, n. 184, p. 43-64, 2002; SILVA, Leonardo Dantas. A instituição do Rei do congo e sua presença nos maracatus. In: (Org). Estudos sobre a escravidão negra. Recife: FUNDAJ/Ed. Massangana, 1988 Ver também: BRANDÃO, Theo. Origens do maracatu. Diário de Pernambuco, 07/03/1957.

24 BRANDÃO, Théo. Folguedos natalinos. Maceió: Depto. de Assuntos Culturais/Conselho Federal de Cultura, 1973.

25 Conforme Aristóteles, mesmo quando se copia, o ser humano produz, cria. Sobre esta questão, ver: ARISTÓTELES. Poética. São Paulo: Nova Cultural, 1996. p. 31-60. (Coleção Os Pensadores. Especialmente as páginas 31 a 60). 


\title{
O problema das origens
}

Quase todos os estudiosos que escreveram sobre os maracatus pensaram ser possível encontrar suas origens. Quando não afirmam, com precisão, o momento exato do seu surgimento, criam um complexo artifício de colocá-lo diretamente na história do Brasil colonial, como se os maracatus fossem "coisa de escravos". Esta ideia de que uma prática ou costume tem uma origem única revela a forte influência da história metódica. A ideia de origem pressupõe que o maracatu tenha surgido de um ponto único, as festas de coroação dos reis e rainhas do congo, apontando na perspectiva de uma história linear, com um começo possível de ser conhecido. Seguramente, posso afirmar que esta obsessão pelas origens das práticas revela também a necessidade de alguns intelectuais em deter o controle "das coisas" a partir do estabelecimento de um suposto começo, como se isso fosse garantia para explicar o estado atual da "coisa", conforme Rocha:

\begin{abstract}
A temática das origens sempre foi uma preocupação de muita gente. [...] Mas, a questão da origem (seja do que for) corre o perigo de ser uma falsa questão. Em primeiro lugar, porque quase que todas as origens estariam perdidas, seriam de improvável localização e o que teria ali acontecido são conjecturas, especulações e hipóteses de difícil comprovação. Em segundo lugar, e aqui está o principal, a origem de uma coisa não garante a explicação do seu estado atual. ${ }^{26}$
\end{abstract}

Na verdade, os maracatus são o resultado de constantes adaptações e recriações de práticas antigas, não sendo possível determinar o seu começo. E desta forma, por favor, estimado leitor e prezada leitora, perdoem os que afirmam ainda hoje serem os maracatus "nascidos das festas de coroação dos reis e rainhas do congo", pois a concepção positivista e linear da História ainda é forte o suficiente para influenciar muitos estudiosos, sobretudo quando não exercem o ofício de historiadores! Sempre que escuto alguém afirmar tal questão, aponto de imediato a imensa quantidade de manifestações culturais assemelhadas aos maracatus nos dias atuais, ou que existiram no passado, como forma de provar que os maracatus nação

26 ROCHA, Everardo P. Guimarães. O que é mito. São Paulo: Brasiliense, 1985. p. 11. 
foram "inventados" em meio a um constante fazer e refazer de práticas. ${ }^{27}$ Sem dúvida que as festas de coroação dos reis e rainhas do congo legaram heranças a este processo, mas isso não autoriza ninguém a insistir na linearidade da história dos maracatus. ${ }^{28}$

Sabe-se que no século XIX existiram grupos variados que eram denominados por maracatus, mas pouco sabemos a seu respeito, se usavam os mesmos instrumentos da atualidade, como eram suas fantasias e que ritmo tocavam. As notícias de jornal sobre os maracatus no final do século XIX indicam que estes eram fortemente perseguidos e rejeitados, ao contrário dos dias de hoje, em que são festejados e proclamados como símbolos máximos da pernambucanidade. Como a história é irônica! No que diz respeito aos sentidos em torno da palavra "maracatu" há uma verdadeira polissemia e, pelo visto, todo e qualquer ajuntamento de negros e batuques que existisse no final do século XIX era denominado como tal..$^{29}$

As mudanças e adaptações são palavras-chave para se entender os maracatus. Para aqueles que continuam acreditando que os maracatuzeiros apenas mantêm uma tradição supostamente inalterada, basta lembrar que as fotos mais antigas das damas de corte dos maracatus de outrora, bem como de Dona Santa (rainha do Maracatu Elefante, entre as décadas de 1930 e 1960), mostram suas fantasias sem a utilização das saias de armação (acessórios feitos por arame e tecido utilizados para manter os vestidos armados; podem também ser feitos com o tecido na goma, sem o arame), o

27 Dentre alguns autores que escreveram sobre as manifestações culturais assemelhadas ao maracatu, ou "originárias das festas e coroação dos reis e rainhas do congo", ver: VALENTE, Waldemar. Outro bailado típico de Goiana: a aruenda. Contraponto, Recife, v. 11, dez. 1949, páginas não numeradas; DUARTE, Abelardo. Folclore negro das Alagoas (áreas da cana-de-açúcar). Maceió: Departamento de Assuntos Culturais, 1974; BRANDÃO, Théo. Folguedos natalinos: Taeiras. Maceió: UFAL/Museu Théo Brandão, 1976; DANTAS, Beatriz Góis. Taieira. Cadernos de Folclore. Rio de Janeiro: Funarte/Gráfica Olímpica Editora, 1977; ROCHA, José Maria Tenório. Folclore brasileiro: Alagoas, Rio de Janeiro: Funarte, 1977; ROCHA, José Maria. Folguedos e danças: sistematização e classificação. Maceió: Secretaria de Educação e Cultura de Alagoas, 1984; TRIGUEIRO, Osvaldo Meira; BENJAMIN, Roberto. Cambindas da Paraíba. Cadernos de Folclore, Rio de Janeiro: Funarte, n. 26, 1978; BENJAMIN, Roberto. Congos da Paraíba. Cadernos de Folclore, Rio de Janeiro: Funarte, n. 18, 1977; BENJAMIN, Roberto. Maracatus, cambindas, pretinhas do Congo: herança negra diversificada no carnaval do interior. Suplemento Cultural do Diário Oficial do Estado de Pernambuco. Recife, fev. 2001, p. 7-9.

28 Maccord mostra, por sinal, que os reis do congo foram contemporâneos aos maracatus. Sobre esta questão, ver: MACCORD, Marcelo. O Rosário de D. Antônio: irmandades negras, alianças e conflitos na história social do Recife. 1848 - 1872. Recife: Editora Universitária da UFPE, 2005.

29 Sobre batuque, Martha Abreu chega a conclusões semelhantes. Ver: ABREU, Martha. $O$ império do divino: festas religiosas e cultura popular no Rio de Janeiro, 1830 - 1900. Rio de Janeiro: Nova Fronteira, 1999. 
que quase não encontramos mais entre os belos vestidos das maracatuzeiras dos maracatus atuais. A utilização das grandes e longas saias de armar da atualidade surge no momento em que as escolas de samba ganham força e fôlego no carnaval da cidade do Recife e não seria estranho pensar que os maracatuzeiros se apropriaram deste recurso performático das porta-bandeiras, adaptando-o em seus maracatus. As primeiras saias de armar são vistas ainda nos anos 1970, o que demonstra serem os maracatus extremamente versáteis em relação às mudanças da vida quotidiana.

As tradições são mantidas pelos maracatuzeiros dentro de um complexo quadro em que a estas são atribuídos novos significados. Nesse jogo, as mudanças são perfeitamente possíveis e isso também deve ter ocorrido entre os maracatuzeiros do passado. Com certeza, as semelhanças entre várias manifestações culturais existentes pelo país afora são um bom indício para pensar esse tenso diálogo que ocorreu entre praticantes de taieiras, congos, cambindas, aruendas e maracatus. ${ }^{30}$ Logo, imaginar que os maracatus surgiram de um ponto único, ou que constituem meras "reminiscências" das festas de coroação dos reis do congo, é retirar a capacidade criativa e humana que homens e mulheres tiveram ao inventarem os maracatus. Aliás, devemos mesmo lembrar que nunca prevaleceu a homogeneidade entre os maracatus e, mesmo hoje, quem for ao Recife vai observar nações com diferentes sotaques rítmicos e cores, isso em meio aos homogeneizadores concursos de carnaval. A diversidade é algo muito forte entre os maracatus nação e a mesma pode ser pensada como pistas de um longo caminho de construção. Portanto, não se pode pensar nos maracatus ou como uma continuidade ininterrupta das coroações dos reis e rainhas do congo ou como uma mera transposição mecânica de práticas africanas para o Brasil, como acreditaram alguns estudiosos.

\section{Maracatus nação e grupos percussivos: cruzamentos e diferenças}

Os maracatus nação pernambucanos se constituem em grupos existentes em uma dada comunidade, formados por pessoas que durante o

30 Sobre pretinhas, aruendas, cambindas, congos, veja-se obras citadas na nota 39. 
carnaval encarnam diferentes personagens, a exemplo de uma corte real, escravos, soldados, vassalos, baianas e batuqueiros. Podem ser definidos como grupos comunitários, em sua maioria, abertos para pessoas "de fora", mas os conflitos e as tensões estão presentes naqueles contextos em que diferentes situações são geradas e negociadas (com os "de dentro") em processos diversos. No geral, praticamente todos os maracatus nação estão sediados em uma comunidade periférica de baixa renda. São majoritariamente compostos por negros e negras (salvo raras exceções!), conforme já afirmei anteriormente, e trazem consigo aspectos que se relacionam com práticas comunitárias.

Os instrumentos musicais e as fantasias usados por estes grupos, quando na ocasião de suas apresentações ao longo do ano ou durante o carnaval, pertencem ao referido maracatu, mesmo que este tenha um dono ou dona. Em geral, há entre os maracatuzeiros e maracatuzeiras uma perspectiva de que o maracatu seja pertencente a uma pessoa, ou seja, possui um dono, que articula o grupo e toma as decisões mais importantes. Isto pode ser mais bem expresso na ideia de que os maracatus possuem um "presidente-dono", o que não retira o caráter comunitário das nações a que irei me referir ao longo deste texto. Destaque-se o fato de que esta compreensão de que tais grupos são posses de natureza individual ou familiar destoa da imensa maioria dos trabalhos que têm o maracatu como tema.

Os maracatuzeiros e as maracatuzeiras possuem estas referências, mas tal informação é quase sempre ocultada nos artigos, livros e trabalhos acadêmicos em geral. Creio que prevalece nestes uma concepção, mesmo que sub-reptícia, que retira a humanidade daqueles e daquelas que praticam o maracatu. Eis uma excelente questão para ser relacionada com as recorrentes monumentalizações das entrevistas dos maracatuzeiros nestas obras. Observo, com certa frequência, diferentes trabalhos em que as afirmações destes são tomadas como verdade, deixando de modo implícito a ideia de que aqueles que integram os maracatus não possuem interesses, logo, não precisam ter suas afirmações cruzadas com outros tipos de documentos. Há exageros diversos, alguns dos quais foram discutidos em um dos meus trabalhos sobre o tema. ${ }^{31}$

31 LIMA, Ivaldo Marciano de França. Maracatus do Recife: novas considerações sob o olhar dos tempos. Recife: Bagaço, 2012. 
Não há uma cobrança de taxas ou mensalidades para integrar, tocar ou desfilar em um maracatu. Ao menos para as pessoas que residem nas comunidades em que os maracatus estão sediados. Isso não significa dizer, entretanto, que as pessoas "de fora" destas comunidades não necessitem pagar para tocar ou desfilar em alguns maracatus, principalmente naqueles que atualmente possuem maior fama, a exemplo do Estrela Brilhante do Recife e do Porto Rico. Na maior parte destes maracatus, portanto, prevalecem relações comunitárias e a cobrança de taxas ou existência de fantasias e instrumentos musicais privados se constitui em exceção.

A extrema maioria dos integrantes dos maracatus nação reside na comunidade, ou próximo de onde o maracatu está sediado. E é por morarem próximos uns dos outros que estão mais dispostos a compartilharem práticas diversas, conferindo o caráter de nação para estes grupos. Estes trazem consigo certa propensão a fazerem o maracatu de modo "coletivo", sem que exista um coreógrafo ou alguém que dite a forma de dançar, ou imponha o modo de costurar, bordar ou fazer qualquer tipo de coisa. Não são grupos dispostos de uma lógica de espetáculo para vender, em que prevaleça uma espécie de "fazer para ser consumido". Estas afirmações, no entanto, não invalidam o fato de serem os maracatus nação influenciados e imersos na espetacularização da cultura, fenômeno bastante presente nos dias atuais. ${ }^{32}$ Estas questões são, a meu ver, as principais diferenças entre as nações de maracatu com os grupos percussivos, por mais que alguns destes venham, no tempo presente, reivindicando a condição de serem nações. Mas esta é outra história!

Os maracatus nação, nesse sentido, compartilham práticas em um mesmo "território". Possuem vínculos com a religião dos orixás, umbanda e com a jurema, podendo ser com as três ao mesmo tempo ou com uma destas apenas. ${ }^{33} \mathrm{O}$ seu espetáculo é fruto de muitas "contribuições" anônimas.

32 CARVALHO, José Jorge de. Espetacularização e canibalização das culturas populares na América Latina. Anthropológicas, Recife, v. 21, n. 1, p. 39-76, jan.-jun. 2010; CARVALHO, José Jorge de. Metamorfoses das tradições performáticas afro-brasileiras: de patrimônio cultural a indústria de entretenimento. Brasília: UnB, Série Antropologia, 2004; DEBORD, Guy. A sociedade do espetáculo. Rio de Janeiro: Contraponto, 1997.

33 LIMA, Vivaldo da Costa. O conceito de "nação" nos Candomblés da Bahia. Afro-Ásia, Salvador, v. 2, n. 12, p. 65-90, jul.-dez. 1976; ORTIZ, Renato. A morte branca do feiticeiro negro: umbanda e sociedade brasileira. 2. ed. São Paulo: Brasiliense, 1991; PINTO, Clélia Moreira. Saravá Jurema Sagrada: as várias faces de um culto mediúnico. Dissertação (Mestrado em Antropologia) - Programa de Pós-Graduação em Antropologia, Universidade Federal de Pernambuco, Recife, 1995; LIMA, Ivaldo Marciano de França. 
Eis o que define um maracatu nação, portanto: território, religião, práticas compartilhadas e espetáculo coletivo.

Por mais que muitos grupos percussivos (sobretudo os olindenses!) reivindiquem para si o título de nação, o fazem por uma questão de mercado ou para dispor de mais espaço, pois não reúnem em torno de si os elementos acima mencionados. E a questão a ser discutida diz respeito aos motivos que fazem com que estes grupos desejem, agora, serem reconhecidos como nações. Estamos diante de um novo fenômeno?

Os grupos percussivos podem ser definidos como agremiações de jovens que dispõem de alguns instrumentos (ou todos) musicais do maracatu. Em regra geral, são formados por pessoas que moram em diferentes localidades, apesar de haver grupos que são constituídos por pessoas de uma mesma comunidade. Se as nações de maracatu variam enquanto instituições, os grupos percussivos também! Pode-se encontrar em um mesmo grupo, que se reúne geralmente nos finais de semana, pessoas que residem em diferentes partes da cidade ou de outros municípios da região metropolitana. Em geral são jovens, brancos e pertencentes às camadas médias urbanas. Os instrumentos pertencem a cada um dos integrantes, que necessitam dispor de um, caso desejem integrar o referido agrupamento, e assim tenham como aprender a tocá-lo.

Há grupos que cobram mensalidades dos seus "sócios", assim como há casos em que os "donos" se constituem em pessoas que articulam os locais para os ensaios, prestam manutenção aos instrumentos, chegando mesmo a vendê-los. Essa situação se repete nos grupos percussivos espalhados pelo Brasil afora. Indivíduos que residem em diferentes localidades, articulados em torno de um grupo que na maioria das vezes sequer dispõe de instrumentos: estes são da ordem do privado.

Uma religião que cura, consola e diverte: as redes de sociabilidade da Jurema sagrada. Cadernos de Estudos Sociais, Recife, v. 20, n. 2, p. 195-208, jul./dez. 2004; MOTTA, Roberto. Catimbós, xangôs e umbandas na região do Recife. In: CONGRESSO AFRO-BRASILEIRO, 3., 1985. Recife. Anais... Recife: Massangana, p. 109-123; MOTTA, Roberto. Religiões afro-recifenses: ensaios de classificação. Anthropológicas (Série Religiões Populares), Recife, v. 2, p. 11-34, jan.-jun. 1997; MOTTA, Roberto; BRANDÃO, Maria do Carmo. Adão e Badia: carisma e tradição no Xangô de Pernambuco. In: SILVA, Vagner Gonçalves da (Org.). Caminhos da alma: memória afro-brasileira. São Paulo: Summus (Edições Selo Negro), 2002. p. 49-87; SALLES, Sandro Guimarães de. À sombra da jurema: a tradição dos mestres juremeiros na umbanda de Alhandra. Anthropólogicas, Recife, v. 15, p. 99-122, 2004; SALLES, Sandro Guimarães de. À sombra da jurema encantada: mestres juremeiros na umbanda de Alhandra. Recife: Editora da UFPE, 2010. 
A maior motivação para o pertencimento a estes grupos percussivos, em linhas gerais, é o encontro para os ensaios musicais, que quase sempre ocorrem nas ruas ou praças do bairro do Recife (também conhecido como Recife antigo), mas é possível vê-los nas ruas da Olinda histórica, mais precisamente próximo à Praça da Preguiça, no Carmo. Grosso modo, pode-se afirmar que o leitmotiv destes jovens é o encontro semanal para tocarem instrumentos que até bem pouco tempo eram considerados "coisas de negros xangozeiros e favelados". ${ }^{34}$

Durante muito tempo, mesmo em Pernambuco, maracatu era uma manifestação cultural segregada nas favelas recifenses, estigmatizados por diferentes motivos. Basta uma simples olhadela nas páginas dos jornais dos anos 1960, 1970, 1980 e 1990 para se constatar que a principal atração do carnaval pernambucano eram as escolas de samba, traduzindo fenômenos semelhantes aos que ocorrem em outros estados do país. Parafraseando Hermano Vianna, o que explica este mistério do maracatu? ${ }^{35}$

Ainda sobre os grupos percussivos, pode-se afirmar que são quase exclusivamente formados por músicos, não havendo, salvo raras exceções, uma corte real ou os demais personagens existentes em um maracatu. ${ }^{36}$ Existem alguns casos de grupos percussivos que dispõem de corte, além de reivindicarem a condição de serem uma nação de maracatu. Vários grupos de Olinda, por exemplo, se apresentam como nações e se utilizam deste termo para se autonomearem, mesmo que tenham uma performance possível de ser enquadrada na lógica do consumo e, por conseguinte, sob a estética e formato de um grupo percussivo.

Estas questões, a meu ver, não serão resolvidas nestas linhas, mas sua indicação mostra que o tema ainda vai render muitos trabalhos e cabelos

34 LIMA, Ivaldo Marciano de França. Identidade negra no Recife: maracatus e afoxés. Recife: Bagaço, 2009. Especialmente o terceiro capítulo.

35 VIANNA, Hermano. O mistério do samba. 5. ed. Rio de Janeiro: Jorge Zahar/Editora da UFRJ, 2004. Nesta obra, o autor chama a atenção para o processo que propiciou ao samba passar da condição de ritmo maldito e proibido para símbolo da identidade nacional brasileira em menos de trinta anos. Por mais que as analogias sejam perigosas, estabeleço uma semelhança entre o samba e o maracatu, respeitando as devidas dimensões e proporções. Se há algumas décadas os maracatus representavam uma manifestação cultural pouco festejada nos carnavais pernambucanos, hoje praticamente reúne em torno de si o maior destaque do tríduo momesco.

36 Sobre um grupo percussivo existente no Rio de Janeiro, ver: ALBUQUERQUE, Aline Valentim. As nações de maracatu de Recife e o maracatu do Rio. Algumas reflexões sobre tradição, ressignificação e mediação cultural. Dissertação (Mestrado em Ciências Sociais) - Programa de Pós-Graduação em Ciências Sociais, Universidade do Estado do Rio de Janeiro, Rio de Janeiro, 2005. 
brancos nos estudiosos do presente e do futuro. Resta apenas dizer que na atualidade há grupos percussivos em diversos estados do país, a exemplo do Rio de Janeiro, São Paulo, Paraná, Santa Catarina, Rio Grande do Sul, Minas Gerais, Paraíba e Ceará. ${ }^{37}$ Também existem grupos percussivos em outros países, a exemplo da Alemanha, França, Rússia, Estados Unidos, Canadá, Espanha, Portugal, Japão, dentre outros. A cada dois anos ocorre na Europa um encontro internacional de grupos e pessoas que fazem maracatu. Para a penúltima edição, realizada em 2010, foram convidados integrantes dos maracatus nação Porto Rico, Encanto da Alegria, Estrela Brilhante do Recife e Leão Coroado (de Olinda). No Brasil, na região sudeste, também ocorrem tais encontros, em geral organizados pelos grupos paulistas. Alguns destes grupos percussivos "internacionais" já dispõem de registros sonoros e em alguns casos existem há mais de quinze anos, a exemplo do Stern der Elbe, da Alemanha. Também há grupos percussivos brasileiros dotados de CD's, a exemplo do Rio Maracatu e de diversos grupos paulistas. Estes dados são apenas alguns detalhes da complexidade que este tema vai ganhando ao longo dos tempos.

A imensa maioria destes grupos percussivos (sejam pernambucanos, brasileiros ou estrangeiros) pode ser entendida como resultado do imenso sucesso alcançado pelo movimento Mangue pernambucano, que foi liderado pelas bandas Nação Zumbi e Mundo Livre S/A. A maior liderança deste movimento, Chico Science, pode ser vista como decisiva para que os "toques" e os sons das "afaias" dos maracatus ganhassem o Brasil e o mundo. ${ }^{38}$ Esta afirmação, entretanto, não deve ser entendida como algo

37 Sobre os grupos percussivos de Santa Catarina, ver: OLIVEIRA, Marco Antônio Carreço de. Reflexões sobre o maracatu nação e o seu desembarque na ilha de Santa Catarina. Trabalho de conclusão de curso (Graduação Música) - Curso de licenciatura, Universidade Estadual de Santa Catarina, Florianópolis, 2006. Existem grupos percussivos em diversos estados do país. Entretanto, estes não podem ser confundidos com os maracatus cearenses, que devem ser entendidos como outra manifestação cultural diversa dos maracatus nação pernambucanos. Sobre os maracatus cearenses, ver: COSTA, G. B. A festa é de maracatu: cultura e performance no maracatu cearense (1980-2002). Dissertação (Mestrado em História) - Programa de Pós-Graduação em História, Universidade Federal do Ceará, Fortaleza, 2009; CRUZ, M. D. Sentidos e significados da negritude no maracatu Nação Iracema. Dissertação (Mestrado em Sociologia) - Programa de Pós-Graduação em Sociologia, Universidade Federal do Ceará, Fortaleza, 2008; MILITÃ̃, J. W. R. Maracatu Az de Ouro: 70 anos de memórias, loas e batuques. Fortaleza: Omni Editora, 2007; SILVA, Ana Cláudia. Vamos maracatucá!!!: um estudo sobre os maracatus cearenses. Dissertação (Mestrado em Antropologia) - Programa de Pós-Graduação em Antropologia, Universidade Federal de Pernambuco, Recife, 2004.

38 VARGAS, Heron. Hibridismos musicais de Chico Science \& Nação Zumbi. Cotia: Ateliê Editorial, 2007; TELES, José (Org.). Meteoro Chico. Recife: Bagaço, 2007; NETO, Moisés. Chico Science: 
automático, pois se após a eclosão do movimento Mangue houve aumento significativo de grupos percussivos mundo afora, não se deve desprezar o fato de que muitos são anteriores ao fenômeno citado. Diga-se de passagem, os articuladores do grupo percussivo denominado Nação Pernambuco reivindicam em alguns dos seus discursos a ideia de que o sucesso atual vivido pelos maracatus nação lhes é tributário do êxito que tiveram ao longo dos anos $1990 .{ }^{39}$

Aliás, parece fundamental afirmar que antes desta nova leva de jovens "maracatuzeiros" sempre ouvia as pessoas envolvidas com maracatu pronunciarem o termo "afaia", ou bombo. Alfaias é a forma mais usual da atualidade e deve ser vista como uma destas tantas inovações a que os maracatus estão submetidos na contemporaneidade. Isso não quer dizer que alfaia seja o único nome usado pelos maracatuzeiros da atualidade. Ainda são pronunciadas palavras como tambor, bombo ou simplesmente afaia. ${ }^{40}$

\section{Nação e grupos percussivos - conceitos despidos de juízos de valor}

Quando estabeleço a existência de diferenças entre dois fenômenos, faço-o por meio de conceitos que tenham como principal motivação a sua devida tradução e entendimento. Os historiadores e as historiadoras necessitam refletir a respeito dos conceitos que utilizam em seus trabalhos para explicar ou narrar determinados contextos. Não devem se apropriar de termos ou conceitos de forma impensada, de modo a corroborarem construções inapropriadas e que, longe de explicar, apenas confundem.

a rapsódia afrociberdélica. Recife: Edições Ilusionistas/Livro Rápido, 2008; NETO, Moisés. Chico Science, Zeroquatro \& Faces do Subúrbio. Recife: Edições Ilusionistas/Livro Rápido, 2008.

39 Em Pernambuco, Nação Pernambuco e Cabra Alada são excelentes exemplos de grupos percussivos anteriores ao sucesso do movimento Mangue. Em Olinda também existiram outros, a exemplo do Leão Negro, do Colégio São Bento, articulado por Jáder Cisneyros. Este foi o responsável pela criação de um grupo na Alemanha, o Stern der Elbe, que pode ser considerado como um dos mais antigos grupos percussivos do mundo.

40 LIMA, Ivaldo Marciano de França. Maracatus-nação: ressignificando velhas histórias. Recife: Bagaço, 2005. 
Os conceitos possuem histórias, circunstâncias e contextos. ${ }^{41}$ Em relação à história dos maracatus nação, fugir dos juízos de valor é fundamental!

Por mais difíceis que sejam as relações entre palavras, "coisas" e conceitos, estes últimos devem servir para mostrar parte das especificidades existentes em dadas realidades. No caso dos maracatus nação, conforme descrito acima, o conceito em questão serve para definir grupos formados por negros e negras (não exclusivamente, conforme já afirmei) que, no geral, residem próximos uns dos outros. São "nações” por disporem de práticas e costumes compartilhados, mas não são grupos étnicos, sobretudo por não possuírem ou exibirem sinais diacríticos, mitos de origem que apontem a ancestralidade com uma divindade ou entidade em comum aos integrantes ou relações baseadas na endogamia..$^{42} \mathrm{Um}$ maracatuzeiro ou maracatuzeira, quando percorre as ruas de alguma cidade, pode perfeitamente ser confundido com qualquer outro cidadão, desde que suas roupas não sejam as mesmas que traja quando por ocasião do tríduo momesco.

Um maracatu nação, nesse sentido, não é uma manifestação cultural superior ou melhor do que um grupo percussivo. São diferentes, posto que se constituam de formas díspares. Maracatu nação é um fenômeno sócio-histórico-cultural exclusivo de Pernambuco. Da forma descrita acima, só existem em Recife, Olinda, Jaboatão e Igarassu. Entretanto, se levarmos ao pé da letra as definições acima encetadas, acerca do formato dos maracatus nação, seguramente alguns dos grupos aceitos como tais não mais poderão ser apresentados ou classificados por este conceito.

Há nações de maracatu que possuem o discurso da vinculação com a religião dos orixás enquanto argumento legitimador para se afirmar como nação. Há grupos que se apresentam como constituídos de intensa prática ritual e demonstram "levar a sério" os preceitos religiosos, mas uma simples pesquisa participante demonstrará que tudo não passa de "argumento para inglês ver”. Há maracatus nação que são articulados por um maracatuzeiro antigo, que empresta sua legitimidade ao grupo, articulado apenas em momentos de carnaval. E existem grupos compostos por jovens, em sua

41 VEYNE, Paul. A História Conceitual. In: LE GOFF, Jacques; NORA, Pierre. História: novos problemas. Rio de Janeiro: Livraria Francisco Alves Editora, 1976. p. 64-88; KOSELLECK, Reinhart. Futuro passado. Rio de Janeiro: Contraponto, 2006.

42 SANSONE, Lívio. Negritude sem etnicidade. Rio de Janeiro/Salvador: Pallas/EDUFBA, 2004; POUTIGNAT, Philippe. STREIFFFNART, Jocelyne. Teorias da etnicidade. São Paulo, UNESP, 1998; BARTH, Fredrik. O guru, o iniciador e outras variações antropológicas. Rio de Janeiro: Contracapa, 2000. 
maioria, que buscam se apresentarem como uma nação, utilizando-se de uma performance para lá de "farsesca", mas o que está em questão não é a verdade ou a mentira, mas tão somente os motivos que justificam essa busca pelo reconhecimento e legitimidade para serem vistos como uma nação maracatuzeira.

\section{Algumas conclusões}

Discorrer a respeito das diferenças em qualquer aspecto é tarefa das mais difíceis, ainda mais quando adentramos o terreno das emoções e paixões, lugar consagrado para os maracatus nação e os grupos percussivos na maior parte dos trabalhos. As diferenças e fronteiras entre estes devem ser sempre entendidas como resultantes de processos e contextos específicos, imersos em jogos e discursos complexos, típicos das construções de identidade. Os maracatus nação não podem ser entendidos como blocos homogêneos, dispostos sob um modelo possível de ser identificado ou explicado de forma simples. Os grupos percussivos também não são iguais e constituídos de um modelo. Entre estes também existem diferenças. Entretanto, para ambos os conceitos existem as permanências e os liames que permitem o enquadramento dos grupos neste ou naquele conceito. Tais considerações foram encetadas ao longo destas páginas.

Definir um maracatu nação, situando-o em meio aos seus tensos e complexos jogos de identidades e discursos, é outra tarefa por demais hercúlea. Creio que agora posso ao menos respirar e dizer: bem, os leitores já sabem que, grosso modo, existem os maracatus de orquestra e os grupos percussivos, que não são iguais aos maracatus nação. Estas diferenças e o debate em torno destas conceituações foram construídos sob o peso dos anos de uma "pesquisa de campo participante" e um duplo lugar, uma vez que ocupei por mais de dez anos o lugar de mestre maracatuzeiro e por outros longos dez anos atuei batuqueiro de diferentes maracatus nação. Concomitante a isto, desenvolvi uma série de estudos acadêmicos, chegando à condição atual em que me encontro. Tudo isto me autoriza a decretar que meus textos e palavras são sinônimos da verdade? Claro que não! Mas nem de longe devem ser desprezados. É interessante, para a construção do co- 
nhecimento, que se possa valorizar a experiência vivida, juntamente com os procedimentos acadêmicos, sem estabelecer hierarquias ou juízos de valor. ${ }^{43}$ As diferenças nas formas de cantar, se relacionar com o sagrado, de confeccionar as fantasias e de reivindicar o passado fazem dos maracatus nação o lugar da diversidade. Seus diferentes estilos de batuque provam isto. E as heranças existem aos montes sob a forma de permanências, bem como as inovações e invenções, apesar de quantidade significativa de estudiosos não enxergarem estas últimas. Enfim, eis mais um pouco desta história, que sem sombra de dúvida não vai parar por aqui e que certamente ainda renderá outras tantas páginas, regadas a muito batuque e toadas! E a história continua!

Recebido em 16 de outubro de 2013. Aprovado em 29 de outubro de 2014.

43 Ver, nesse sentido, o artigo "Trabalho de campo, reciprocidade e elaboração de textos etnográficos: o caso Maurice Leenhardt" de: CLIFFORD, James. A experiência etnográfica. Antropologia e literatura no século XX. Rio de Janeiro: Editora UFRJ, 2002. 